\title{
THE GENETICS OF SEED AND TUBER DORMANCY IN THE CULTIVATED POTATOES
}

\author{
N. W. SIMMONDS \\ John Innes Institute, Bayfordbury, Hertford
}

Received 4.iii.64

\section{INTRODUCTION}

AT an early stage in work on the physiology of potato seeds it became clear that material of the cultivated potatoes was highly heterogeneous as to the expression of dormancy. A study of the genetic control of dormancy was therefore begun, few such studies having been reported in other plants, though of considerable significance from the viewpoint of crop evolution. It later became clear that, in the potatoes, seed and tuber dormancy are correlated, a result of some intrinsic interest and one which has bearing on breeding techniques (Simmonds, $\left.\mathrm{I}_{96} 6_{3} a, b\right)$. The purpose of this paper is to describe the results of these studies.

\section{MATERIALS AND METHODS}

\section{Plant materials}

All the stocks used were derived from cultivated stocks maintained in the Commonwealth Potato Collection. Most of the native South American cultivars fall into two great groups, the diploids and their autotetraploid derivatives, the Andigena Group. Field plantings of very mixed stocks of diploids and tetraploids separately, made at Hertford in I959, yielded large bulks of open-pollinated seed which were the sources of the selection experiment described below. In addition, clones of certain cultivated diploids, maintained in the Collection, were also used. They belonged to two cultivar groups: the Phureja Group (abbreviated phu) and the Stenotomum Group (stn); the former characteristically bears tubers that are but slightly dormant, while the latter bears tubers which are more strongly or even very deeply dormant, a difference which reflects human selection pressure in their evolution (Dodds, I962; Dodds and Paxman, I962).

\section{Estimation of seed dormancy}

The methods used were based on general studies of the expression of dormancy in potato seeds, studies which have been described in detail elsewhere (Simmonds, 1963a). Crosses were made in the glasshouse during the summer and all berries were picked at six weeks of age and extracted at once; dormancy was either tested immediately or, if that were impossible, the dry seed was stored over silica gel in the laboratory for the requisite few weeks, such storage being known to prevent the normal decline of dormancy after harvest. Germination was tested on lots of 50 seeds placed on moist filter paper in petri dishes in daylight in the laboratory. Total percentage germination after four weeks was taken as an inverse measure of dormancy; this is an arbitrary choice and one which leads to insensitivity at both ends of the range of dormancy. Time taken to 50 per cent. of final germination would, as a measure, be more sensitive in detecting differences between low dormancies but also breaks down 
at the high end because extremely dormant seeds may rot before they germinate. The method adopted, however, covers the big differences very well and is simple in use.

Since low viability could give a false appearance of dormancy, plates were either retained for the necessary time to check the point or dormancy was broken by addition of gibberellic acid. A very few aberrant results were thus discarded.

The question of reproducibility of results on seed dormancy is of obvious importance. As described below, replicate tests made in parallel in a single season have reasonably low error variances which can be used to make comparisons within the season's results. Between-seasons differences, however, might be expected to be important and one set of data, in fact, confirms this. Ten crosses among the cultivated diploids were tested in both $196 \mathrm{I}$ and 1962 , all in reciprocal (see p. 500); a pooled error variance derived from the two (homogeneous) within-Years errors is available. The analysis shows that there is a large Years effect, 1962 giving lower dormancy than I96I; there are also large between Crosses and Reciprocal effects (as revealed by the original analyses and of no interest in the present context); by contrast, the two interactions with Years are both relatively small, though one is significant, showing that the genetic results are reasonably reproducible despite the large effect of season. Detailed numerical comparisons can therefore properly be made only between materials tested in parallel in one season.

\begin{tabular}{|c|c|c|c|c|}
\hline Item & & d.f. & V. & V.R. \\
\hline I. Years . & . & I & ז867 & $42 \cdot 6$ \\
\hline 2. Crosses & . & 9 & $68 \mathrm{I}$ & 15.5 \\
\hline 3. Reciprocals & . & 10 & 333 & $7 \cdot 6$ \\
\hline 4. $\mathrm{Y} \times \mathrm{C}$ & . & 9 & $\begin{array}{l}335 \\
137\end{array}$ & $3 \cdot 1$ \\
\hline 5. $\mathrm{Y} \times \mathrm{R}$. & . & 9 & 75 & $\mathrm{I} \cdot 7$ \\
\hline 6. Error & . & $6 \overrightarrow{6}$ & 44 & - \\
\hline
\end{tabular}

(Items I-4 significant at I per cent. level or beyond.)

\section{Selection methods}

Selection for and against dormancy was carried out by laying fresh seed (harvested in the early autumn) on moist filter paper in the laboratory and picking the first seedlings to germinate as being of low dormancy, the last as of high dormancy. Some care was necessary in the final stages because the last few per cent. of seed was often inviable. Low dormancy selections were carried on over the winter in the glasshouse, with supplementary lighting to inhibit tubering and such vegetative propagation by cuttings as was necessary to bring them into flower synchronously with the late selections in the following summer. Subsequent selection of families to carry on the lines in any one year was based on the seed dormancy tests carried out in the previous autumn.

\section{Estimation of tuber dormancy}

All plants were grown in the glasshouse or in frames outdoors during the summer months. Groups of plants judged to be at the same stage of maturity were harvested and tested as a group; since individuals in a family often differed in maturity, it was sometimes necessary to harvest a family in two or three lots at intervals of one to three weeks. As soon as possible after harvest, tubers were laid in covered trays of moist peat in the glasshouse and twice-weekly observations of sprouting were made. The period of dormancy* of a tuber was taken as the time in days from harvest to the

* Equivalent to the "rest period" of Emilsson (1949). See Discussion, below, for comment. 
appearance of a sprout at the surface of the peat. Usually, three tubers per plant were tested, though not all plants provided sufficient and a few tubers rotted before sprouting.

Tubers were roughly classified as large (more than $2 \mathrm{~cm}$. in mean diameter), medium $(\mathrm{I}-2 \mathrm{~cm}$.) and small $(\mathrm{I} \mathrm{cm}$. or less) in the expectation that sprouting time would be correlated with size ( $c f$. Emilsson, 1949). This expectation was realised: the larger tubers sprouted more quickly in low-dormancy families and the same trend, though less marked, was also apparent in medium-dormancy families; the effect nearly disappeared, however, in deeply dormant families, in which tuber size had but slight effect. This is simply illustrated by reference to the diploid families tested in I962 (see p. 496). Frequencies with which larger tubers sprouted more quickly/less quickly than smaller ones were as follows: early families $72 / 19$, medium $60 / 18$, late 46/39. The question of correcting results for tuber size is discussed below.

As with seed dormancy, so the question of reproducibility of results on tuber dormancy is obviously important. Much agronomic experience with the north temperate cultivated potatoes shows that tuber dormancy, though undoubtedly clonally characteristic, is very variable in expression with season and place (Emilsson, 1949; Burton, 1963). The same was true of the material used in these studies, as shown by subsidiary tests in which stocks examined first in the autumn of 1962 were regrown in the glasshouse and retested during the following winter, spring and early summer. Though the results of the two trials were reasonably highly correlated $(r=+0 \cdot 75[32],+0 \cdot 67[22]$ and $+0 \cdot 86[32]$ for three distinct batches of material) all the winter dormancy times were longer than the corresponding autumn times. A second cycle of retesting of the same stocks, grown in the summer of 1963 and tested in the autumn of that year gave similar results. Correlation coefficients were $+0.73[34],+0.85[17]$ and $+0.90[52]$ which are all highly significant but, once again, mean sprouting times were greater in the repeat than in the original test. The correlations between tests show that dormancy is clonally characteristic but the mean differences between them show that detailed quantitative comparisons can properly only be made between stocks raised and tested in parallel. Regressions derived from these trials, however, allow reasonable corrections for between-year effects to be applied (see p. 498).

In estimating the mean tuber dormancy of a family raised from seed (e.g. those listed in tables 3 and 4), it was necessary to avoid the bias that might be introduced by correlated seed and tuber dormancy. Thus untreated seed that retained some dormancy when sown in the spring would tend to give families from which the more deeply dormant fractions had been eliminated, so biasing the estimate of tuber dormancy. In order to minimise this bias, the seed was treated with gibberellic acid before sowing, thus breaking any residual dormancy (Simmonds, I963a).

\section{Statistical analysis}

Seed germination figures, in the form of percentages based on 50-seed plots, were transformed to angles. Trials with one set of data showed that means and variances were uncorrelated even when substantial numbers of values were below 5 per cent. or above 95 per cent. With 50 -seed plots, the expected error variance is about 16 ; as in physiological experiments with potato seeds (Simmonds, 1963a), observed variances were generally somewhat larger. Thus three (somewhat heterogeneous) variances estimated for diploid material in 1962 gave, when pooled, a value of $3^{8.8}(\mathrm{n}=34)$; these were based upon replicate seed lots sown from single berries. A similar pooled variance based upon four (homogeneous) estimates of variance of seed lots from different berries of the same cross was $46 \cdot 6(n=94)$, which is not significantly greater (V.R. $[94,34]=\mathrm{I} \cdot 20$ ). Replicate berries within one season therefore agree quite well-though one exception to this will be noted below.

In the analysis of tuber dormancy, days to sprouting was used as a variate. The data provided estimates of the mean effect of tuber size within groups of families and 
an attempt was made to correct for this factor by adjusting the results for large and small tubers by the appropriate addition or subtraction. Since the distribution of tuber sizes was very similar for all families, means were virtually unaffected by this procedure though variances were, as expected, slightly reduced. The effect was not large, however, and (especially since some of the size-adjustments were rather poorly estimated) the attempt was abandoned.

\section{RESULTS}

The selection of low and high seed dormancy in diploids and tetraploids

The results of three generations of selection are summarised in figs. I and 2. After the primary selection for early and late germination in the initial bulk of seed, the four lines were carried on by sibcrossing (for the diploids) or by selfing and sibcrossing (for the tetraploids. Parents for the following generation were grown from remnant

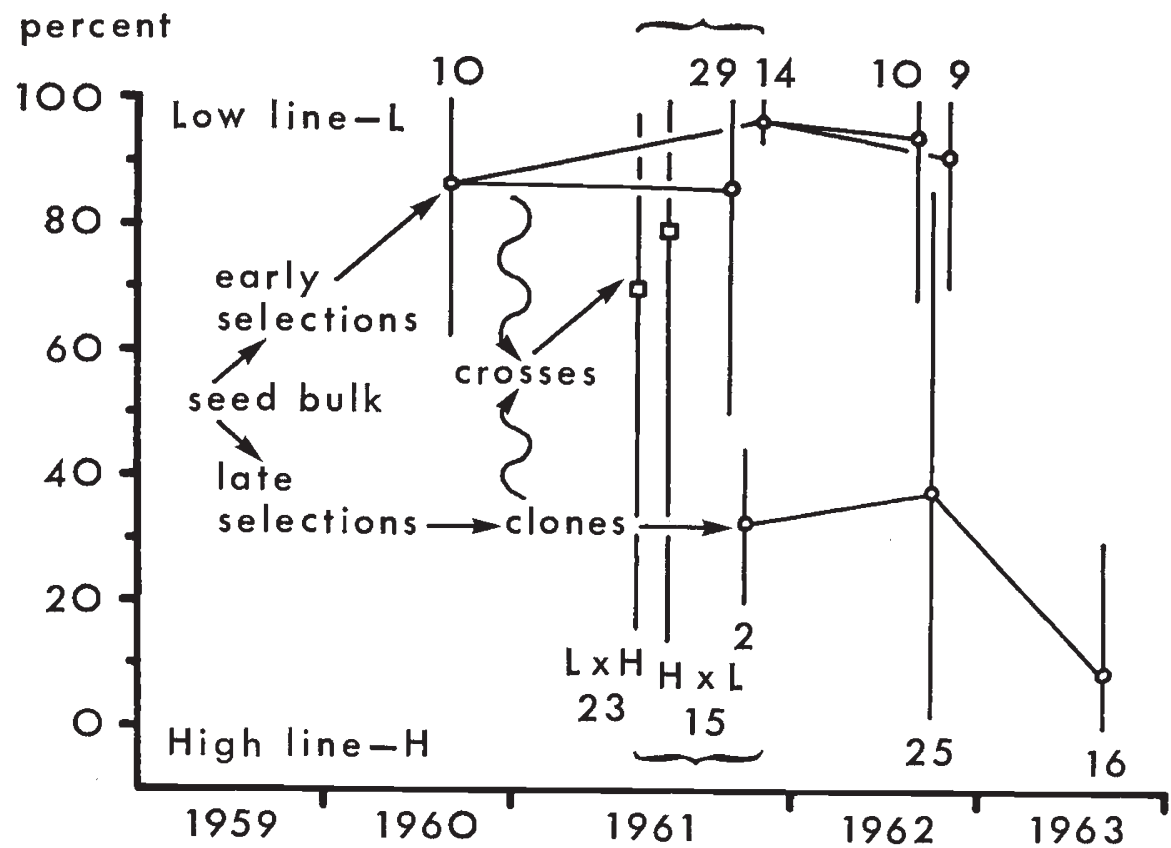

Fig. I.-Seed dormancy selection in the cultivated diploids: means and ranges of 4-week germination data in successive generations. Numbers of combinations tested for each entry indicated in figures; group of 1961 crosses contained in brackets include those tested in 1962 for tuber dormancy (see text).

seed selected on the basis of dormancy tests and further selection was practised during germination of the $1960-6 \mathrm{I}$ generation but not subsequently. Selection rates were approximately $\mathrm{I}$ per cent. in $1959-60$ and $10-40$ per cent. in $1960-6 \mathrm{I}$, when relatively small quantities of seed were available.

The vagaries of fertility (as usual in potatoes) were such that an exactly symmetrical pattern of selection and testing could not be 
followed. Nevertheless, the general trends of response are clear: both diploids and tetraploids readily yielded high and low dormant lines in which seed germination at 4 weeks approached $\mathrm{r}$ oo and o per cent. respectively. Results of intercrossing high and low lines were somewhat erratic but dormancy was generally intermediate. Many crosses were tested in reciprocal: for the diploids there was no evidence that reciprocal effects were common (V.R. $[22,94]=47 \cdot 0 / 46 \cdot 6$ ), though one pair of observations was suggestive. For the tetraploids,

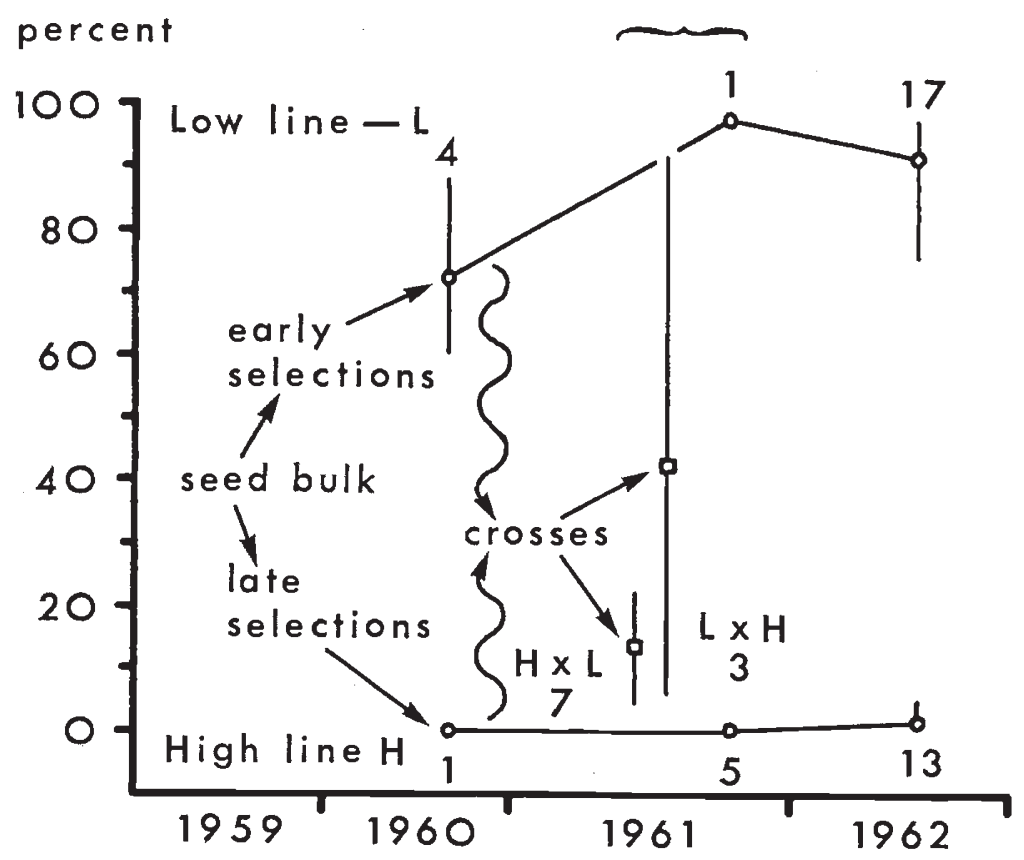

FIG. 2.-Seed dormancy selection in the cultivated tetraploids: means and ranges of 4-week germination data in successive generations. Numbers of combinations tested for each entry indicated in figures; group of 1961 crosses under the bracket include those tested in 1962 for tuber dormancy (see text).

there were too few data for formal test but a strong suggestion in two crosses that the cross low female by high male produced progeny of lower dormancy ( 90 and 92 per cent.) than the reciprocals ( 46 and ro per cent. respectively). More detailed evidence on reciprocal effects is given below (p. 500).

In summary, it appears that the parental seed bulks (and therefore the cultivated diploid and Andigena Group populations from which they came) were highly heterogeneous and responded readily to selection.

\section{A diallel cross in the cultivated diploids}

A diallel cross was made in triplicate between six cultivated diploids. The parents were necessarily selected on the basis of seed and pollen fertility and, as the results subsequently showed, did not 
well cover the lower range of dormancy. One pair of parents turned out to be inter-incompatible, as shown by failure to set and by stylar squash preparations; missing values were calculated and the degrees of freedom in the analysis adjusted accordingly. Results are given in table I. There is one relatively small non-additive effect (as shown

TABLE I

A diallel cross in the diploid potatoes; the inheritance of seed dormancy

\begin{tabular}{|c|c|c|c|c|c|c|}
\hline q 0 & $8_{3} 6$ & 979 & I 776 & $22 \mathrm{II}$ & 2749 & I855 \\
\hline 836 & - & IOO & 99 & 300 & $9^{\mathrm{I}}$ & 94 \\
\hline 979 & IOO & - & 88 & 97 & $7 I$ & I 00 \\
\hline $\begin{array}{l}1776 \\
2211\end{array}$ & $\begin{array}{l}96 \\
84\end{array}$ & $\begin{array}{l}87 \\
82\end{array}$ & $\overline{80}$ & 93 & $\begin{array}{l}78 \\
28\end{array}$ & 97 \\
\hline 2749 & $\begin{array}{l}44 \\
92\end{array}$ & 93 & gI & 82 & 20 & $\begin{array}{l}49 \\
89\end{array}$ \\
\hline $\begin{array}{l}1855 \\
\end{array}$ & 95 & 98 & 99 & 97 & 79 & - \\
\hline
\end{tabular}

Diallel cross-mean germinations per cent. Values significantly exceeding reciprocals in bold face, those less than reciprocals in italic.

\begin{tabular}{|c|c|c|c|c|c|c|c|}
\hline & Item & & & & d.f. & V. & V.R. \\
\hline $\begin{array}{l}\text { Total effects } \\
\text { remainder }\end{array}$ & : & : & : & : & $\begin{array}{l}5 \\
8\end{array}$ & $\begin{array}{r}\text { I } 666 \\
234\end{array}$ & $\begin{array}{r}39.5 \\
5.6\end{array}$ \\
\hline$\underset{\text { remainder }}{\text { Reciprocals }}$ & : & : & : & : & $\begin{array}{l}5 \\
9\end{array}$ & $\begin{array}{r}\text { I } 62 \\
67\end{array}$ & $\begin{array}{r}27.5 \\
1.6\end{array}$ \\
\hline Error & . & . & . & . & $5^{6}$ & 42 & - \\
\hline
\end{tabular}

Diallel cross-analysis of variance (angles).

\begin{tabular}{|c|c|c|c|c|c|}
\hline Clone & Males & Females & Sums & Differences & $\begin{array}{c}\text { Tuber } \\
\text { dormancy } \\
\text { (days) }\end{array}$ \\
\hline & & & & & \\
\hline 836 & $+6 \cdot 5$ & $+12 \cdot 8$ & $+19 \cdot 3$ & $6 \cdot 3$ & 16 \\
979 & $+4 \cdot 1$ & $+5 \cdot 0$ & $+9 \cdot 1$ & $0 \cdot 9$ & 23 \\
1776 & $+2 \cdot 5$ & $+1 \cdot 5$ & $+4 \cdot 0$ & $1 \cdot 0$ & 14 \\
2211 & $+2 \cdot 1$ & $-19 \cdot 2$ & $-17 \cdot 1$ & $21 \cdot 3$ & 20 \\
2749 & $-17 \cdot 7$ & $-5 \cdot 9$ & $-23 \cdot 6$ & $11 \cdot 8$ & 17 \\
1855 & +2.5 & +5.8 & $+8 \cdot 3$ & $3 \cdot 3$ & 67 \\
\hline
\end{tabular}

Diallel cross-summary. For explanation of last column see p. 496.

by the Remainders); but there are large differences between parents and between reciprocals. Thus clone 836 transmits markedly low dormancy, clones 22 I I and 2749 relatively high dormancy. Reciprocal effects all lie in the two latter clones but in opposite directions; that is, as female, 22I I transmits high but 2749 transmits low dormancy. The results therefore suggest predominantly additive polygenic control but show that reciprocal effects can be significant among the diploids. 


\section{Correlated seed and tuber dormancy in the cultivated diploids}

In 196 I an extensive set of crosses between cultivated diploid clones was made and seed dormancy was tested in the autumn of that year. Remnant seed was grown the following season from a selected set of these crosses and the plants were tested for tuber dormancy. The results therefore provide an opportunity to test for correlation between the two dormancies.

Results on seed dormancy are summarised in table 2. All crosses tested were made in reciprocal but it was not possible to complete the diallel. Ten duplicate berries were available to provide an estimate of error. Of the II clones used, five are assigned in the Collection to the Stenotomum Group (i.e. they have more or less

TABLE 2

Seed dormancy in the Phureja and Stenotomum Groups of diploid potatoes

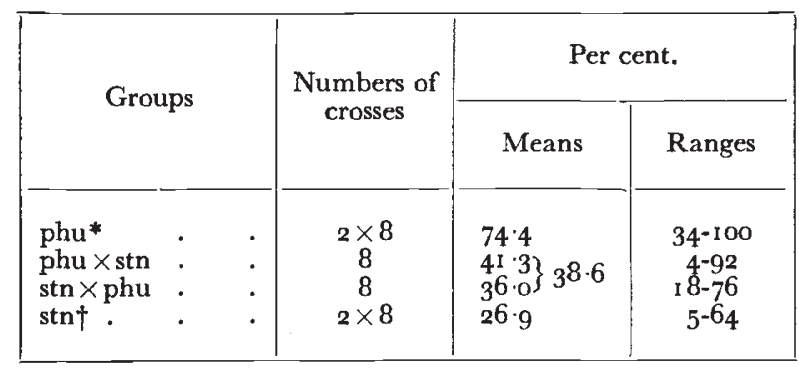

* Clones-836, 979, 1 776, $2211,2231$.

$\dagger$ Clones-494, 1082, 1674, 1837, 2749, 2795.

dormant tubers) while six are assigned to Phureja, having little or non-dormant tubers. There are large differences between cultivar groups; thus Stenotomum bears more dormant seeds than Phureja a difference which is parallel to the behaviour of their tubers. There is, however, some overlap between the Groups, which are each quite variable, and good evidence of reciprocal effects (V.R. for reciprocals in $\mathrm{phu} / \mathrm{stn}=247 / 53$ and in phu 338/53). Reciprocal effects all lay in combinations of members of the Phureja Group, conspicuously in clones 836 and 1776 , which tended to transmit low dormancy as females, and clone 2211, which did the reverse. Thus the various reciprocal effects tend to cancel out and, as a result, the means for phu $\times$ stn and stn $\times$ phu agree quite well (table 2).

Estimates of tuber dormancy of the selected families are given in table 3 , along with the relevant seed dormancy data and assessments of parental tuber dormancy. It is clear that the tuber dormancy of the progeny is correlated both with the parental behaviour and with the dormancy of the seed lots from which they were grown. It is also clear that the considerable reciprocal differences in seed behaviour are not reflected in the tubers: all six reciprocals tested agree very closely. Error variances, it will be noted, are strongly correlated with means. 
Nearly all the families gave evidence of differences between individuals in respect of tuber dormancy. The relevant variance ratio was significant in all except one Phureja cross ( $1776 \times 22$ I I) and two Stenotomum crosses (1082 $\times 2749$ and $1674 \times 1082)$; in each case, however, the reciprocal cross gave evidence of variation so it is clear that all combinations tested showed genetic heterogeneity in this respect. Genetic variances are highest in the stn crosses, lower in the phu $\times$ stn hybrids and lower still in the phu crosses.

TABLE 3

Seed and tuber dormancy in the edible diploid potatoes

\begin{tabular}{|c|c|c|c|c|c|c|c|}
\hline Source & $\begin{array}{c}\text { Parentage } \\
\text { (C.P.C. numbers) }\end{array}$ & $\begin{array}{l}\text { Parental } \\
\text { tuber } \\
\text { dormancy }\end{array}$ & $\begin{array}{c}\text { Seed } \\
\text { dormancy }\end{array}$ & $\begin{array}{c}\text { Tuber } \\
\text { dormancy }\end{array}$ & $\begin{array}{c}\text { Number } \\
\text { tested }\end{array}$ & $\begin{array}{l}\text { Error s.d. } \\
\text { (per cent.) }\end{array}$ & $\begin{array}{l}\text { Genetic } \\
\text { variance }\end{array}$ \\
\hline \multirow[t]{2}{*}{ phu $\times$ phu } & $\begin{array}{l}1776 \times 2211 \\
2211 \times 1776\end{array}$ & $\begin{array}{l}\mathrm{L}, \mathrm{L} \\
\mathrm{L}, \mathrm{L}\end{array}$ & $\begin{array}{r}100 \\
54\end{array}$ & $\begin{array}{l}14 \pm 2 \cdot 1 \\
17 \pm 2 \cdot 5\end{array}$ & $\begin{array}{l}20 \\
20\end{array}$ & $\begin{array}{l}7 \cdot 2(51) \\
5 \cdot 1(30)\end{array}$ & $\begin{array}{r}5 \\
24\end{array}$ \\
\hline & $\begin{array}{c}979 \times 2211 \\
2211 \times 979\end{array}$ & $\begin{array}{l}\mathrm{L}, \mathrm{L} \\
\mathrm{L}, \mathrm{L}\end{array}$ & $\begin{array}{l}72 \\
34\end{array}$ & $\begin{array}{l}15 \pm 1 \cdot 9 \\
16 \pm 2 \cdot 8\end{array}$ & $\begin{array}{l}16 \\
15\end{array}$ & $\begin{array}{l}4 \cdot 6(31) \\
3 \cdot 8(23)\end{array}$ & $\begin{array}{r}8 \\
25\end{array}$ \\
\hline $\begin{array}{l}\text { stn } \times \text { phu } \\
\text { phu } \times \text { stn }\end{array}$ & $\begin{array}{c}2749 \times 836 \\
836 \times 2749\end{array}$ & $\begin{array}{l}\text { M, L } \\
\text { L, M }\end{array}$ & $\begin{array}{l}40 \\
92\end{array}$ & $\begin{array}{l}29 \pm 4 \cdot 5 \\
29 \pm 5 \cdot 2\end{array}$ & $\begin{array}{l}20 \\
2 \mathrm{I}\end{array}$ & $\begin{array}{l}10 \cdot 4(36) \\
10 \cdot 0(35)\end{array}$ & $\begin{array}{r}64 \\
113\end{array}$ \\
\hline $\begin{array}{l}\text { stn } \times \text { phu } \\
\text { phu } \times \text { stn }\end{array}$ & $\begin{array}{l}1082 \times 2211 \\
2211 \times 1082\end{array}$ & $\begin{array}{l}\mathrm{H}, \mathrm{L} \\
\mathrm{L}, \mathrm{H}\end{array}$ & $\begin{array}{r}18 \\
4\end{array}$ & $\begin{array}{l}5^{6} \pm 8 \cdot 3 \\
5^{8} \pm 7 \cdot 0\end{array}$ & $\begin{array}{l}20 \\
20\end{array}$ & $\begin{array}{l}17 \cdot 7(32) \\
18 \cdot 7(32)\end{array}$ & $\begin{array}{l}237 \\
130\end{array}$ \\
\hline \multirow[t]{2}{*}{$\operatorname{stn} \times \operatorname{stn}$} & $\begin{array}{l}1082 \times 2749 \\
2749 \times 1082\end{array}$ & $\begin{array}{l}\mathrm{H}, \mathrm{M} \\
\mathrm{M}, \mathrm{H}\end{array}$ & $\begin{array}{l}14 \\
23\end{array}$ & $\begin{array}{l}82 \pm 11 \cdot 1 \\
76 \pm 13 \cdot 0\end{array}$ & $\begin{array}{l}20 \\
19\end{array}$ & $\begin{array}{l}31 \cdot 9(39) \\
25 \cdot 7(34)\end{array}$ & $\begin{array}{l}282 \\
5^{1} 7\end{array}$ \\
\hline & $\begin{array}{l}1082 \times 1674 \\
1674 \times 1082\end{array}$ & $\begin{array}{l}\mathrm{H}, \mathrm{M} \\
\mathrm{M}, \mathrm{H}\end{array}$ & $\begin{array}{l}6 \\
5\end{array}$ & $\begin{array}{r}9^{8} \pm 17 \cdot 5 \\
102 \pm 11 \cdot 9\end{array}$ & $\begin{array}{l}16 \\
19\end{array}$ & $\begin{array}{l}25 \cdot 4(26) \\
29 \cdot 2(29)\end{array}$ & $\begin{array}{l}475 \\
216\end{array}$ \\
\hline
\end{tabular}

Column 3-L low, $M$ medium, $\mathrm{H}$ high dormancy; columm 5-means (days) \pm fiducial limits.

Polygenic control of seed and tuber dormancy is therefore fairly clear and the two dormancies are highly correlated. That specific clonal effects can override the correlation in some cases is shown by observations included in table I (bottom right-hand column). The parental tuber dormancies of the clones used in the diallel cross were not obviously related to the level of seed dormancy that the clones transmitted and, further, agree rather poorly with some of the results of table 3. It is impossible, on the evidence, to decide where the discrepancies lie.

\section{Correlated seed and tuber dormancy in the selection lines}

A set of results similar to those just described is available for the seed dormancy selection lines. That is, seed lots tested for dormancy in the autumn of 1961 were grown in 1962 and tested for tuber dormancy in the autumn and winter of that year (table 4). Because all plants were grown and tested together, direct comparison with the Phureja/ Stenotomum results is legitimate. In addition, similar data are also 
available for the products of an extra cycle of selection in the diploid high dormancy line ( $c f$. fig. I, bottom right-hand corner); these tests were necessarily carried out a year later than the others included in the table so that comparisons must be made with some reserve.

It will be seen that selection for low seed dormancy in the diploids produced lines that had the low tuber dormancy characteristic of the Phureja Group while the contrary selection moved tuber dormancy

TABLE 4

Seed and tuber dormancy in the selection lines (cf. figs, $I$ and 2)

\begin{tabular}{|c|c|c|c|c|c|c|c|}
\hline Source & Families & Cross & $\begin{array}{c}\text { Seed } \\
\text { dormancy }\end{array}$ & $\begin{array}{l}\text { Tuber } \\
\text { dormancy }\end{array}$ & $\begin{array}{c}\text { Number } \\
\text { tested }\end{array}$ & $\begin{array}{l}\text { Error s.d. } \\
\text { (per cent.) }\end{array}$ & $\begin{array}{l}\text { Genetic } \\
\text { variance }\end{array}$ \\
\hline \multirow{6}{*}{$\begin{array}{l}\text { Diploid } \\
\text { dormancy } \\
\text { selection }\end{array}$} & $\begin{array}{l}62 / 51 \\
62 / 52 \text { (reciprocal) }\end{array}$ & $\begin{array}{l}\mathbf{L} \times \mathbf{L} \\
\mathbf{L} \times \mathbf{L}\end{array}$ & $\begin{array}{l}100 \\
100\end{array}$ & $\begin{array}{l}20 \pm 3 \cdot 0 \\
17 \pm 2 \cdot 6\end{array}$ & $\begin{array}{l}29 \\
29\end{array}$ & $\begin{array}{l}6 \cdot 3(32) \\
9 \cdot 0(52)\end{array}$ & $\begin{array}{l}49 \\
24\end{array}$ \\
\hline & $\begin{array}{l}62 / 57 \\
62 / 58 \text { (reciprocal) }\end{array}$ & $\begin{array}{l}\mathrm{L} \times \mathrm{L} \\
\mathrm{L} \times \mathrm{L}\end{array}$ & $\begin{array}{l}50 \\
68\end{array}$ & $\begin{array}{l}38 \pm 8 \cdot 9 \\
33 \pm 7 \cdot 4\end{array}$ & $\begin{array}{l}18 \\
19\end{array}$ & $\begin{array}{l}12 \cdot 5(33) \\
13 \cdot 2(40)\end{array}$ & $\begin{array}{l}315 \\
172\end{array}$ \\
\hline & $\begin{array}{l}62 / 55 \\
62 / 56 \text { (reciprocal) }\end{array}$ & $\begin{array}{l}\mathrm{L} \times \mathrm{H} \\
\mathrm{H} \times \mathrm{L}\end{array}$ & $\begin{array}{l}64 \\
62\end{array}$ & $\begin{array}{l}25 \pm 4 \cdot I \\
39 \pm 7 \cdot 8\end{array}$ & $\begin{array}{l}19 \\
20\end{array}$ & $\begin{array}{r}577(23) \\
14.4\left(3^{8}\right)\end{array}$ & $\begin{array}{r}70 \\
234\end{array}$ \\
\hline & $\begin{array}{l}62 / 53 \\
62 / 54 \text { (reciprocal) }\end{array}$ & $\begin{array}{l}\mathrm{H} \times \mathrm{H} \\
\mathrm{H} \times \mathrm{H}\end{array}$ & $\begin{array}{l}20 \\
45\end{array}$ & $\begin{array}{l}60 \pm 9 \cdot 2 \\
59 \pm 10 \cdot 4\end{array}$ & $\begin{array}{l}34 \\
29\end{array}$ & $\begin{array}{l}22 \cdot 9\left(3^{8}\right) \\
18 \cdot 4\left(3^{1}\right)\end{array}$ & $\begin{array}{l}490 \\
564\end{array}$ \\
\hline & $\begin{array}{l}63 / 1 \\
63 / 2 \text { (reciprocal) }\end{array}$ & $\begin{array}{l}\mathrm{H} \times \mathbf{H} \\
\mathrm{H} \times \mathbf{H}\end{array}$ & $\begin{array}{r}2 \\
10\end{array}$ & $\begin{array}{r}93 \pm 7 \cdot 9 \\
101 \pm 11 \cdot 1\end{array}$ & $\begin{array}{l}28 \\
13\end{array}$ & $\begin{array}{r}10 \cdot 3(11) \\
7 \cdot 6(8)\end{array}$ & $\begin{array}{l}418 \\
403\end{array}$ \\
\hline & $\begin{array}{l}63 / 3 \\
63 / 4\end{array}$ & $\begin{array}{l}\mathrm{H} \times \mathrm{H} \\
\mathrm{H} \times \mathrm{H}\end{array}$ & $\begin{array}{r}18 \\
6\end{array}$ & $\begin{array}{l}\text { 119t } 5.8 \\
\text { lo3t } 6.6\end{array}$ & $\begin{array}{l}40 \\
37\end{array}$ & $\begin{array}{l}10 \cdot 4(9) \\
10 \cdot 0(10)\end{array}$ & $\begin{array}{l}289 \\
365\end{array}$ \\
\hline $\begin{array}{l}\text { Tetraploid } \\
\text { dormancy } \\
\text { selection }\end{array}$ & $\begin{array}{l}62 / 59 \\
62 / 62 \\
62 / 63 \\
62 / 61\end{array}$ & $\begin{array}{l}\mathrm{L} \times \mathrm{L} \\
\mathrm{L} \times \mathrm{H} \\
\mathrm{H} \times \mathrm{L} \\
\mathrm{H} \times \mathrm{H}\end{array}$ & $\begin{array}{r}98 \\
28 \\
22 \\
0\end{array}$ & $\begin{array}{r}37 \pm 6 \cdot 0 \\
106 \pm 19.9 \\
101 \pm 14 \cdot 7 \\
13^{8} \pm 8 \cdot 0\end{array}$ & $\begin{array}{l}30 \\
15 \\
18 \\
33\end{array}$ & $\begin{array}{l}20 \cdot 9(57) \\
21 \cdot 2(20) \\
12 \cdot 2(12) \\
19 \cdot 2(14)\end{array}$ & $\begin{array}{r}109 \\
1226 \\
913 \\
333\end{array}$ \\
\hline
\end{tabular}

Column 3-L.low line, $\mathrm{H}$ high line; column $5-$ means (days) \pm fiducial limits.

towards the Stenotomum expression. Exactly similar trends are apparent in the tetraploid lines though the actual levels of tuber dormancy are, for comparable combinations, all higher than in the diploids.

As with the Phureja/Stenotomum results, all combinations tested gave evidence of genetic heterogeneity (all variance ratios significant); variances are somewhat erratically correlated with means but tend to vary with year, being lower in 1963 than in 1962 ; and the tuber dormancies of reciprocal crosses, with one exception, agree closelythey do not reflect reciprocal differences in seed dormancy. The one exception is provided by the diploid families $62 / 55$ and $62 / 56$ (table 4 ) which agreed in seed dormancy but differed in the behaviour of their tubers: in view of the very close agreement between all other reciprocals tested, the most likely explanation seems to be that some 
unconscious selection occurred in one family in the seedling stage (see p. 49I). Genetic variances among the diploids are generally similar to those determined for the phu/stn families and show the same trend, falling with selection towards low dormancy; further, the 1963 generation of high dormancy selection appears to have brought with it decline of genetic variance such as would surely be expected to occur when selection was pushed far enough. The tetraploids agree in showing a low genetic variance in the low dormant line but the hybrid families are anomalously high in this respect.

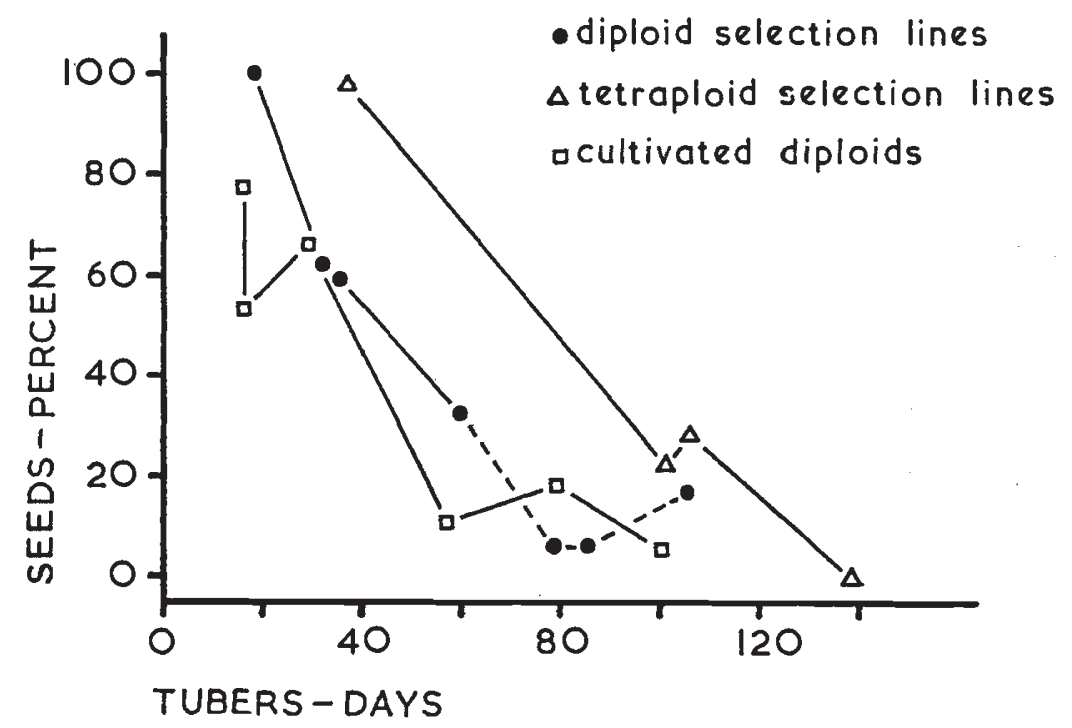

FIG. 3.-The relation between seed and tuber dormancy in the cultivated potatoes. Family means, based on data of tables 3 and 4 , combining reciprocals; for explanation of dashed part of diploid selection line curve, see text.

Replicate tests of individual clones done in 1962 and 1963 gave, as described above, good correlations between years but considerable mean differences. Thus the ${ }^{2} 963$ families given in table 4 (lines 9-I 2 ) cannot be directly compared with the preceding generation. The replicate tests of diploid selection line stocks however provided a regression by which the 1963 means could reasonably be corrected to a 1962 base. The corrections lie between 14 and 20 days and the revised means are as follows: $63 / 1-73,63 / 2-83,63 / 3-$ Io 5 and $63 / 4-85$ days.

The results of tables 3 and 4 that bear on the correlation between seed and tuber dormancy are shown in condensed form in fig. 3 . The adjusted 1963 data are plotted as dotted lines. The general similarity of behaviour of the established cultivated diploids to the diploid seed selection lines will be apparent, together with the parallel behaviour, but generally higher tuber dormancy levels, of the tetraploids. 

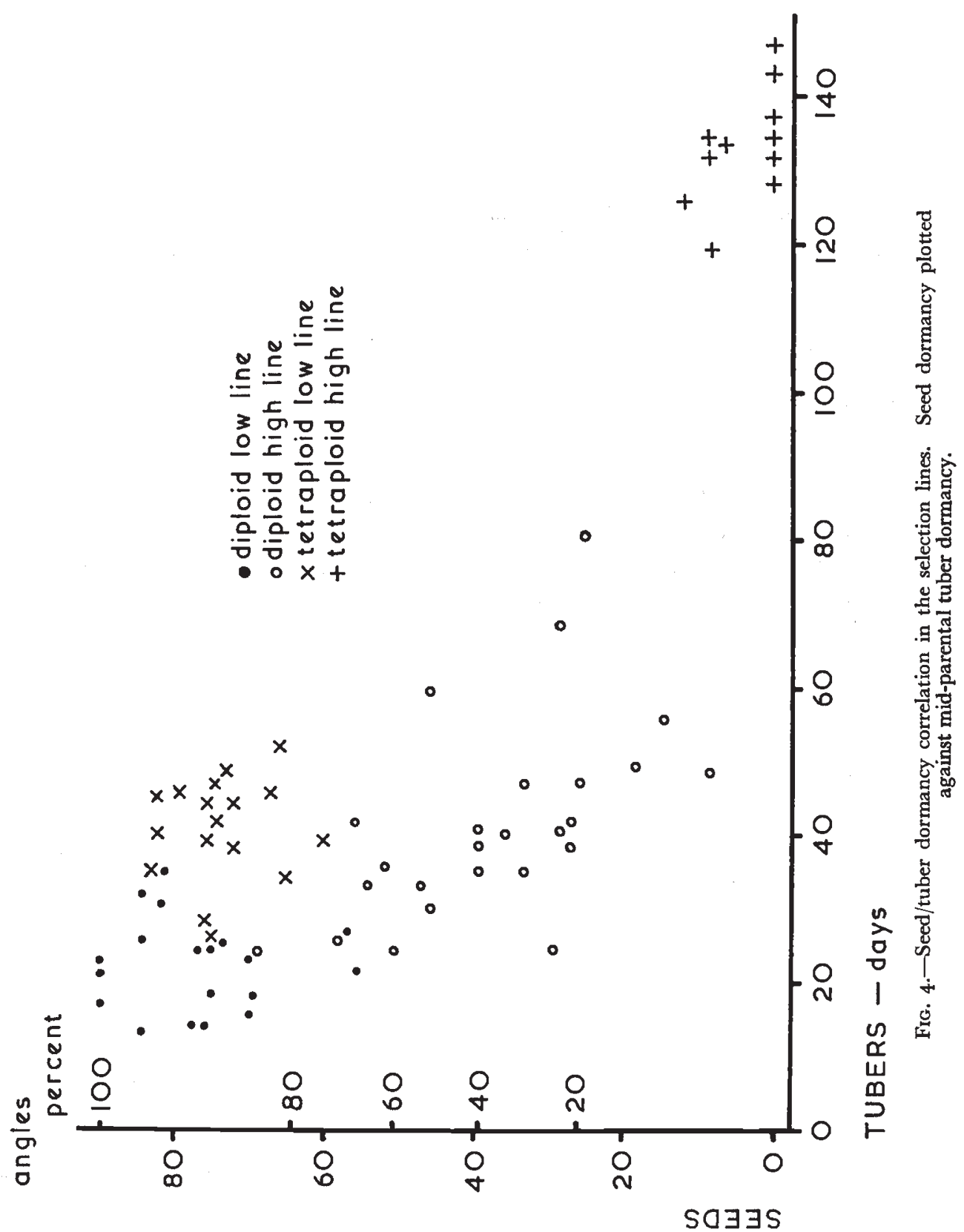
Sample plants of the High and Low diploid and tetraploid lines that were tested for tuber dormancy in 1962 were sib-pollinated in the summer of that year and the resultant seed lots later tested for dormancy ( $c f$. figs. I and 2). The data, summarised in fig. 4, provide an opportunity to make a test complementary to those already described, i.e. to compare the seed dormancies of families of which the parents had already been tested for tuber dormancy. The general relation between the two dormancies is again quite clear. Of the four correlation coefficients within groups, only that for the diploid High line is significant $(r=-0.54, n=23)$ though the overall relations within diploids and tetraploids are, of course, clear enough. Evidently, the other three groups have moved so far towards fixation of the dormancy genes that there is insufficient variability left to reveal the correlation. Significantly, the diploid High line was one generation behind the others and, in the following generation, provided evidence of further response to selection (figs. I and 3 ).

\section{A test of reciprocal difference in seed dormancy}

Evidence of the occurrence of reciprocal differences in seed dormancy has been given above and one combination was chosen for replicated test. The cross of the diploid High line clones $6 \mathrm{I} / \mathrm{I} 74$ and $6 \mathrm{I} / \mathrm{I} 75$ gave 20 per cent. and 45 per cent. in the two directions, I $74 \times 175$ and $I 75 \times I 74$ (fig. I, I 96 I data). In 1962 eight crosses in each direction were made and two samples of 50 seeds were sown from each berry. The means were: $174 \times 175-4 \mathrm{I}^{1} \cdot 4$ per cent.; I $75 \times 174-5 \mathrm{I} \cdot 9$ per cent. Final viability averaged $96-99$ per cent. The analysis of variance (angles) shows that the reciprocal difference is by far the largest effect and that Replicates (i.e. differences between berries tested against within-berry variance as error) is suggestively large, the only instance in which this has been found to be so (see p. 49I).

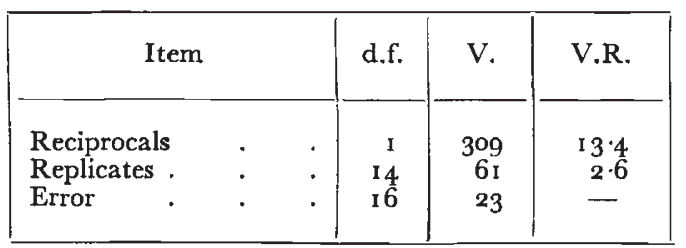

Thus the reciprocal effect is undoubtedly real and consistent in direction as between the two years, though the years themselves clearly differ (seed less dormant in 1961 than in 1962 (see p. 490)).

\section{A survey of tuber dormancy in the cultivated potatoes}

The tuber dormancies of samples of potato clones of various origins were tested, with results summarised in table 5. With the exception noted in the table, all material was grown in the glasshouse during the same period of time (summer, 1962) and tested in parallel. The 
one outstanding difference is between the Phureja Group and the rest; the other three South American Groups are markedly more dormant than the Phureja Group and all cover much the same range of dormancy times. It will be seen from the comparison made in the right-hand column that selection of high and low seed dormancy in the Andigena Group has produced a range of tuber dormancies that markedly transgresses that shown by a sample of established South American clones. It has, however, recently been found that occasional Andigena clones have been selected in South America for low dormancy so there are the beginnings of a tetraploid analogy to the Phureja Group among the diploids (John Innes Institute, I963).

TABLE 5

Tuber dormancy in the groups of cultivated potatoes

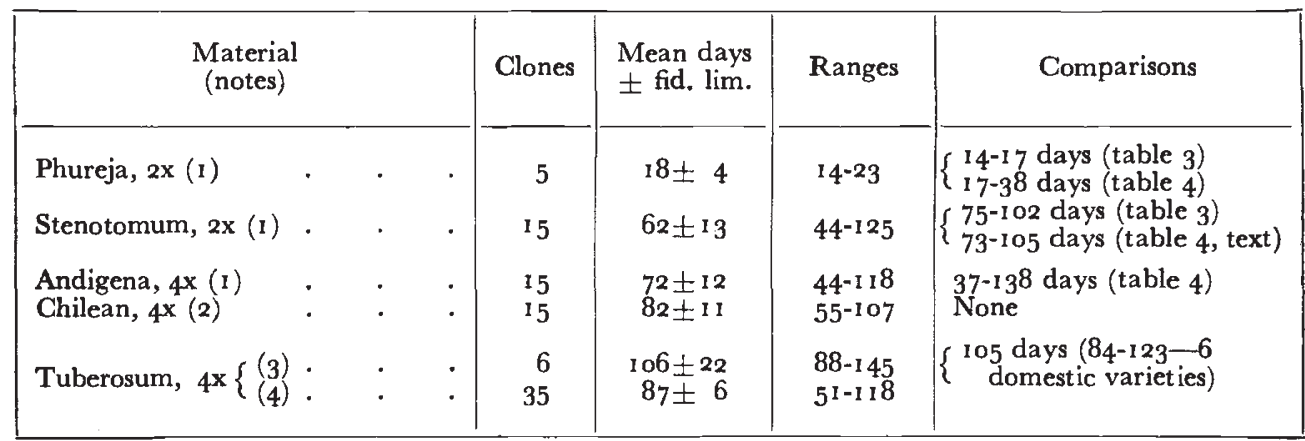

Notes,-(1) C.P.C. clones; (2) C.P.C. clones: for comments on this group of potatoes see Simmonds (1964); (3) random unselected seedlings; the last column refers to a test of six British domestic clones (field-grown stocks); (4) random seedlings tested in the summer of 1963 (see text).

The six Tuberosum Group seedlings tested in 1962 were all deeply dormant and the results agree well with those from six established commercial clones. Selection in north temperate latitudes has therefore favoured deep dormancy. The figures for Tuberosum Group seedlings given in the last line of the table were obtained in 1963 and are therefore not directly comparable with the preceding; but they agree in indicating fairly deep dormancy in the Group. These data come from an experiment in which an unsuccessful attempt was made to select for high and low dormancy at the seed level. Though there were significant differences between plants (V.R. [34, 92] = I0.3) the reason for failure was clearly that the seedlings taken for test were all more or less deeply dormant, thus reflecting earlier phases of selection in the Group: low dormancy combinations had been eliminated from the sample tested.

\section{DISCUSSION}

The seeds and tubers of wild potato species are, in general, dormant when first harvested; and so are those of the majority of cultivated 
potatoes. The recognition of a small group of non-dormant cultivated diploids, however, goes back many years and it has more recently become clear that non-dormant triploids and tetraploids also occur: over a considerable area of the Andes, collection of cultivars under the local name " chaucha" (= early) yields diploids, triploids and tetraploids (Dodds and Paxman, I962). Some of the diploids, at least, are quick-maturing as well as quick-sprouting and appear to have evolved in response to human selection for clones adapted to growth all the year round in the warmer valleys. Evidence now begins to accumulate that this evolution may have occurred independently in different places (John Innes Institute, I963). The results reported in this paper make it clear that selection of polygenic variability in both diploids and tetraploids was the genetic basis of the change. The direction of change was from highly dormant to less dormant and the results given here show that it was accompanied by the expected fall in genetic variance. At the high end, selection has not been pushed far enough to restrict genetic variance for there is no agronomic reason to do so; but there are signs (p. 498) that this point may have been reached in the diploid high dormancy line. Clearly, selection could be pushed far beyond an acceptable agronomic level.

Perhaps the most striking feature of the present results is the high correlation that exists between seed and tuber dormancy. The implication that the two dormancies are under a common biochemical control is clear.* Unfortunately, the nature of that control is yet unknown, despite the existence of a very considerable body of work on tuber dormancy in the potatoes (reviews by Emilsson, I949; Burton, 1963). Potato stocks having contrasted states of dormancy should provide good material for biochemical study, better material, at least, than has been generally available to physiologists, who have had to make do with more or less deeply dormant Tuberosum clones. A second implication of the seed-tuber correlation is that the plant breeder's selection towards high or low dormancy may be facilitated; contrariwise, it seems possible, even probable, that breeding stocks sown as untreated seed in the winter, six months after harvest, may have suffered unconscious selection towards low dormancy in the resulting clones. Fortunately, avoidance of this bias by a dormancy-breaking treatment of the seed is simple.

Different investigators of potato tuber behaviour have used different terminologies to describe dormancy and different methods to measure it. Thus Emilsson (1949), in a leading review of the subject, distinguishes between "rest period" (the obligate period of nonsprouting after harvest even under conditions favourable to sprouting)

* Similar correlations might perhaps occur in other plants, for example tree fruits such as apples and peaches in which bud break in spring might be predicted to be related to seed dormancy. In strawberries there is certainly significant variation in both seed and runner dormancy which, again, might well prove to be correlated (Hedley Williams, personal communication). 
and "dormant period" (the period of non-sprouting under stated low-temperature storage); the first is always less than or, at most, equal to the second. The distinction is essentially an agronomic one and it seems unfortunate that the generally used botanical word " dormancy" should be applied to an arbitrarily chosen feature of storage of concern only to the potato agronomist. Further, it would be unreasonable to apply different words to what is clearly the same behaviour in seeds and tubers; since potato seeds undoubtedly show "dormancy" in the ordinary botanical sense of the word, it seems advisable to use this term for both seeds and tubers.

The diversity of methods used to assess tuber dormancy by various workers makes numerical comparisons of results very difficult, indeed virtually impossible. In a survey of some 50 European varieties Emilsson found a range of rest periods from 5 to ig weeks with a marked mode at 9-12 weeks. Burton (1963) found a mode of about 9 weeks (range 3.5 to i5 weeks) in a sample of i I British varieties. Despite much variability due to season, maturity, tuber size and so forth, these wide ranges undoubtedly largely represent genetic variation between clones. Hence there is probably plenty of room for selection by the plant breeder (though a small trial reported here was unsuccessful-p. 50I). The mean dormancy of Tuberosum material determined in the present work was about I 5 weeks (table 5), which is rather higher than the modes given by Emilsson and Burton (determined by different methods).

Finally, three other studies of the genetic control of dormancy have been reported: in oats by Barber and Quisenberry (1923) and by Johnson (1935a,b); in peanuts (Arachis) by Hull (1937); and in a clover (Trifolium subterraneum) by Morley (1958-see also Ballard, 1958, I96I). In all three, inheritance was polygenic, though some of the oat data were interpreted otherwise. In this they resemble the potatoes but, unlike them, have presumably developed their varying dormancies by direct selection at the level of the seed itself; in the cultivated potatoes, it is reasonable to suppose that selection operates at the tuber level and seed dormancy follows.

Other studies that bear on the genetic control of seed behaviours are those of Harper and McNaughton (1960) on poppies, of Honing (1930) on tobacco and of Kugler (195I) on Arabidopsis. The last two are mainly concerned with the genetic control of a light-demand for germination rather than with dormancy. Several examples of reciprocal differences in seed behaviour are given for the poppies and the tobacco.

\section{SUMMARY}

The South American cultivated potatoes show a wide range of seed and tuber dormancies. Selection for high and low seed dormancies was effective in both diploids and tetraploids and the results, together with those of a diallel cross among cultivated diploids, 
indicated broadly additive polygenic control of dormancy. Reciprocal differences were frequent and operated in both directions. Seed and tuber dormancies are highly correlated so that selection for one automatically implies selection for the other; common biochemical control is inferred and the correlation is of some significance for the potato breeder. Selection among the European potatoes has generally favoured fairly deep dormancy (in tubers that have to be stored over a long winter). Among the South American potatoes, various levels of dormancy have been selected in accord with local requirements. In discussion it appears that the four plants in which dormancy has been studied genetically (oats, peanuts, a clover, potatoes) all show polygenic control of the character.

\section{REFERENCES}

BALLARD, L. A. T. 1958. Studies of dormancy in the seeds of subterranean clover (Trifolium subterraneum L.). I. Aust. F. biol. Sci., II, 246-26o.

BALLARD, L. A. T. I961. Studies of dormancy in the seeds of subterranean clover (Trifolium subterraneum L.). II. Aust. F. biol. Sci., I4, I 73-1 86.

BARBER, R. J., AND QUISENBERRY, K. S. 1923. Delayed germination and the origin of false wild oats. 7. Hered., I4, 267-274.

BuRton, w. G. 1963. Concepts and mechanism of dormancy. In The Growth of the Potato, ed. by Ivins and Milthorpe. Butterworth, London.

DoDDs, K. S. 1962. The classification of the cultivated potatoes. In Correll, D. S., The Potato and its Wild Relatives. Texas Res. Found., pp. 517-539.

DODDs, K. S., AND PAXMAN, G. J. 1962. The genetic system of cultivated diploid potatoes. Evolution, $16,154-167$.

EMILsson, B. 1949. Studies on the rest period and the dormant period in the potato tuber. Acta agric. suec., 3, 189-284.

HARPER, J. L., AND McNAUGHTON, I. H. 1960. The inheritance of dormancy in interand intraspecific hybrids of Papaver. Heredity, 15,31 5-320.

HoNiNG, J. A. 1930. Nucleus and plasma in the heredity of the need of light for germination of Nicotiana seeds. Genetica, 12, 441-468.

HULL, FRED H. 1937. Inheritance of rest periods of seeds and certain other characters in the peanut. Bull. Fla agric. Exp. Sta., 314, 46.

JOHN INNES INSTITUTE. 1963. Rep. Innes Inst., 1962, 53, 21 -31.

Johnson, L. P. v. 1935a. General preliminary studies of the physiology of delayed germination in Avena fatua. Canad. F. Res., C., 13, 283-300.

Johnson, L. P. V. 1935b. The inheritance of delayed germination in hybrids of Avena fatua and $A$. sativa. Canad. F. Res., C., 13, 367-387.

KUGLER, I. I95I. Untersuchungen über das Keimverhalten eniger Rassen von Arabidopsis thaliana. Ein Beitrag zum Problem der Lichtkeimung. Beitr. Biol. $P f$., $28,211-243$.

MORLEY, F. н. W. 1958. The inheritance and ecological significance of seed dormancy in subterranean clover (Trifolium subterraneum L.). Aust. F. biol. Sci., I I, 261-274. simmonds, N. W. 1963a. Experiments on the germination of potato seeds. Europ. Potato 7., 6, 45-6o, 69-76.

simmonds, N. W. $1963 b$. Correlated seed and tuber dormancy in the potatoes. Nature, Lond., 197, 720-721.

simmonds, N. W. 1964. Studies of the tetraploid potatoes. I. The variability of the Andigena Group. F. Linn. Soc. (Bot.), 58, $46 \mathrm{6}-474$. 